\title{
The influence of husbands' approval on women's use of prenatal care: Results from Yirgalem and Jimma towns, south west Ethiopia
}

\author{
Belay T. Biratu ${ }^{1}$, David P. Lindstrom ${ }^{2}$
}

\begin{abstract}
Background: The utilization of formal prenatal care services in Ethiopia could generally be described as low by international standards. While this is attributed to the lack of access to formal maternal health-care service, which is an important barrier to prenatal care, other important socio-cultural barriers to service utilization also exist.

Objective: The aim of this study is to identify the relative influence of the attitudes and background characteristics of husbands and wives on prenatal care utilization, and in particular to identify the role of a husband's approval on prenatal care.

Methods: Data were collected from 1,750 women in a community-based survey of maternal health conducted in Yirgalem town and its surrounding rural areas, as well as in Jimma Town in 1997. Multivariate regression models were used to identify: (1) the relationship between the determinants of whether a woman wanted a pregnancy and whether a husband approves of prenatal care, and (2) the influence of a husband's approval on care utilization net of pregnancy wantedness and other factors.

Results: It was found out that a husband's approval has a greater effect on prenatal care utilization than whether a wife wanted the pregnancy or a wife's level of education. It was also found that the impact of a husband's approval on prenatal care is greatest among women under the age of 20.
\end{abstract}

Conclusion: The findings of this study underscore the importance of targeting men when designing interventions that are intended to raise the awareness and use of prenatal health-care services. [Ethiop.J.Health Dev. 2000;20(2):84-92]

\section{Introduction}

Prenatal care is an effective health intervention tool for reducing the risk of maternal morbidity and mortality, particularly in places where the general health status of women is poor. Studies indicate that the risk of maternal morbidity and mortality is significantly higher among women who do not receive prenatal health-care services compared to women who do so (1). Prenatal care is also associated with fewer complications during pregnancy, higher birth weights, and lower rates of perinatal, neonatal, infant and child mortality (2). The gains from expanded prenatal health-care utilization are greatest in countries such as Ethiopia where fertility and mortality are high. According to the 2000 Ethiopian Demographic and Health Survey (DHS), only 27 percent of mothers who have had a live birth in the five years preceding the survey, received prenatal care from health professionals (3).

Research on the use of prenatal care tends to focus on women's characteristics, including whether or not the pregnancy was wanted. Women who wanted to get pregnant or planned a pregnancy tend to be more highly motivated to seek prenatal care in order to ensure a healthy birth, than women who did not want the pregnancy (4). Studies of maternal health-care utilization consistently find that pregnancy resulting from a woman's conscious will is an important determinant of using prenatal care (5-7). Women's health seeking behavior, however, is influenced by intervening social relations that may prescribe the range and extent of their autonomous action. In traditional societies where restrictions are placed on women's freedom of movement and contact with unrelated men, a husband's attitude toward prenatal care may be an important factor in determining whether prenatal care is received. While men's approval of formal prenatal care may be culturally patterned along ethnic and religious lines, there may also be significant variation within ethno-religious groups based on levels of education, exposure to modern healthcare practices, individual interpretations of religious values and adherence to traditional beliefs. It is, therefore, expected that having a husband who approves of prenatal care significantly increases the likelihood that a woman uses prenatal care, irrespective of the husband's background characteristics.

The actual influence of a husband's beliefs on a woman's health seeking behavior, however, may vary by a woman's background characteristics that are associated with variations in autonomy such as age and education. Women's autonomy in health seeking behavior has been shown in other studies to increase with age and education (8-9). Therefore, it is expected that a husband's approval will have less influence on the use of prenatal care among older and more educated women than among younger women and women who have little or no education.

Limited access to formal maternal health-care services is certainly an important factor for the low rate of prenatal care, but the non-acceptance of formal health-care

\footnotetext{
${ }^{1}$ Email: Belay_Biratu@brown.edu, ${ }^{2}$ Department of Sociology and Population Studies and Training Center, Brown University, Providence, Rhode Island, 02912, U.S.A Email： David_Lindstrom_1@brown.edu Tel. (401) 863-3765
} 
service and the failure to recognize its benefits are important barriers to service utilization even in areas where the services are available. The identification of socio-cultural barriers to the utilization of maternal health-care services is an important component in the design of effective strategies for increasing prenatal care utilization. This study examines the relative influence of husbands' and wives' attitudes and background characteristics on prenatal care utilization in a sample of women drawn from two urban areas and one rural area in south west Ethiopia. The primary objective of this study is to assess the influence of a husband's approval of prenatal care on the use of prenatal health-care services.

\section{Methods}

To examine our hypotheses, data were used from a community based survey of maternal health conducted in 1997 in the Oromia and Sidama regions of south west Ethiopia by investigators from Jimma University. The Yirgalem and Jimma Survey of Maternal Health collected fertility and health related data from 1,750 randomly sampled women in two regional towns and the nearby rural communities. A two stage sampling design was used in which Urban Dweller Associations and Rural Peasant Associations were randomly selected in the first stage, followed by households at the second stage. The survey questionnaire used several screening questions to select for interviews, women who had had live births within 12 months of the survey. In the first stage, a total of nine urban and four rural associations were selected in Yirgalem while 10 urban associations were selected in Jimma Town.

Yirgalem town is located in the Southern Nations, Nationalities and Peoples Region, in one of the most densely populated zones of Ethiopia. It has a population of approximately 25,000 . Jimma Town has a population of approximately 93,000 (10), and is the administrative and commercial center of Western Oromia Region. At the time of the survey, the population of Yirgalem town was served by one hospital and one health center which operate in the town, and seven health stations operating in the surrounding rural communities. Basic prenatal health-care services were also available at the publicly operated facilities free of charge, and at private clinics for a fee. Jimma town had one hospital, one health center, three health stations and five private clinics.

Because the Yirgalem and Jimma Survey focused on maternal health, only women who had childbearing experience were interviewed. One of the unique advantages of the survey is that it collected information on the husband's or partner's characteristics including attitudes toward prenatal care. The 2000 Ethiopia DHS for example, asked husbands about whether the last pregnancy was wanted, but it did not ask about approval of prenatal care. Ninety percent of the women interviewed for the Yirgalem and Jimma Survey were in formal unions or marriages, and 10 percent were in unstable unions or informal relationships. In both cases, the women were asked to report on their husband or partner. In this paper the term husband is used to refer to both husbands and partners. In the multivariate models used in this study, a control variable was included for union types to distinguish between formal marriages (husbands) and informal or unstable relationships (partners).

The Yirgalem and Jimma Survey also recorded the timing of the first prenatal care visit to a modern health institution during the most recent pregnancy that ended in a live birth. Pregnancy wantedness was measured by a question asking whether the pregnancy was planned or unplanned but wanted, or whether it was unwanted. A husband's attitude toward prenatal care was measured by the woman's response to a question on whether her husband approved, was neutral, or disapproved of her going to a modern health center for prenatal care. In this analysis the neutral and disapproved responses are grouped together.

The analysis is divided into two parts. First a bivariate probit regression model is used to examine the determinants of whether the woman wanted the pregnancy and whether the husband approves of prenatal care. The bivariate probit regression model jointly estimates regressions for two outcome variables, and includes a common correlation term (rho) that estimates the degree to which the two outcomes are jointly determined $(11,12)$. It is possible that wanting a pregnancy and approval of prenatal care are codetermined, particularly given that the woman is responding for her husband. For instance, women who do not want a pregnancy may also be less likely to report that their husband approves of prenatal care. A rho significantly different from zero suggests that one decision is endogenous, or is determined, by the other. A rho equal to zero suggests that whether a woman wanted the pregnancy and whether her husband approves of prenatal care are independently determined. After the relationship between pregnancy wantedness and husband's approval was examined, a complementary loglog regression model was used to estimate the impact of attitudes and background characteristics on the hazard of first use of prenatal care in a given trimester. The complementary log-log model takes the form:

\section{$\log \left[-\log \left(1-P_{i t}\right)\right]=\beta_{0}+\beta_{1} X_{i 1}+\cdots+\beta_{k} X_{i k}$}

where, $\boldsymbol{P}_{i t}$ is the conditional probability that woman $i$ starts prenatal care in trimester $t ; \boldsymbol{X}_{\boldsymbol{i l}} \ldots \boldsymbol{X}_{\boldsymbol{i k}}$ are characteristics of the woman and her husband; and the $\boldsymbol{\beta}$ 's are estimated from the data. When the $\boldsymbol{\beta}$ 's are exponentiated they give a relative risk interpretation. 


\section{Results}

Sixty-nine percent of the women in the sample were found to have received formal prenatal care during their last pregnancy. This figure is considerably higher than the level reported for Ethiopia as a whole in the 2000 DHS and reflects the urban bias of the Yirgalem and Jimma sample. Both Jimma and Yirgalem towns have relatively well developed health infrastructures, and the rural communities sampled around Yirgalem town had access to health facilities in the town. Physical access to health facilities is, therefore, not a major barrier to the utilization of prenatal health-care services in the study areas.

Table 1 presents selected sample characteristics and their relationships to prenatal care. One-half of the women in the sample wanted their most recent birth, while threefourths

Table 1: Descriptive Statistics for Selected Variables, Women of Reproductive Age with at Least One Live Birth, Yirgalem and Jimma Survey of Maternal Health, 1997

\begin{tabular}{|c|c|c|}
\hline Variables & $\begin{array}{l}\text { Percentage of } \\
\text { women }\end{array}$ & $\begin{array}{l}\text { Percentage of women who } \\
\text { received prenatal care }\end{array}$ \\
\hline \multicolumn{3}{|l|}{ Woman wanted pregnancy } \\
\hline No & 50.2 & 61.5 \\
\hline Yes & 49.8 & 77.0 \\
\hline \multicolumn{3}{|c|}{ Partner approves of prenatal care } \\
\hline No & 25.6 & 39.7 \\
\hline Yes & 74.4 & 79.4 \\
\hline \multicolumn{3}{|l|}{ Woman's education } \\
\hline No Schooling & 31.3 & 49.7 \\
\hline Primary & 29.8 & 66.9 \\
\hline Post-primary & 38.9 & 86.8 \\
\hline \multicolumn{3}{|l|}{ Husband's education } \\
\hline No Schooling & 15.2 & 50.0 \\
\hline Primary & 24.9 & 58.5 \\
\hline Post-primary & 59.9 & 78.6 \\
\hline \multicolumn{3}{|l|}{ Woman's ethnicity } \\
\hline Sidama & 35.3 & 51.1 \\
\hline Oromo & 17.5 & 78.5 \\
\hline Amhara & 19.1 & 81.4 \\
\hline Other & 28.1 & 78.0 \\
\hline \multicolumn{3}{|l|}{ Husband's ethnicity } \\
\hline Sidama & 38.5 & 56.5 \\
\hline Oromo & 18.6 & 77.6 \\
\hline Amhara & 14.2 & 82.7 \\
\hline Other & 28.6 & 74.3 \\
\hline \multicolumn{3}{|l|}{ Woman's religion } \\
\hline Orthodox & 45.7 & 76.7 \\
\hline Protestant & 33.4 & 55.9 \\
\hline Muslim & 17.7 & 77.4 \\
\hline Others & 3.2 & 57.1 \\
\hline \multicolumn{3}{|c|}{ Woman's sex preference for most recent birth } \\
\hline No preference & 45.7 & 60.1 \\
\hline Son & 31.4 & 76.9 \\
\hline Daughter & 22.9 & 77.1 \\
\hline \multicolumn{3}{|l|}{ Union type } \\
\hline Stable & 89.5 & 71.7 \\
\hline Unstable & 10.5 & 48.6 \\
\hline \multicolumn{3}{|l|}{ Woman's age } \\
\hline$<20$ & 12.9 & 60.2 \\
\hline $20-24$ & 30.2 & 74.3 \\
\hline $35+$ & 56.9 & 68.6 \\
\hline \multicolumn{3}{|l|}{ Parity } \\
\hline 1 & 29.0 & 73.2 \\
\hline $2-3$ & 32.9 & 72.4 \\
\hline $4-5$ & 19.0 & 70.0 \\
\hline $6+$ & 19.0 & 57.1 \\
\hline \multicolumn{3}{|l|}{ Prior infant death } \\
\hline None & 86.1 & 70.7 \\
\hline One or more & 13.9 & 60.2 \\
\hline \multicolumn{3}{|c|}{ Prior prenatal care utilization } \\
\hline No & 53.5 & 55.9 \\
\hline Yes & 46.5 & 84.6 \\
\hline \multicolumn{3}{|l|}{ Place of residence } \\
\hline Yirgalem, rural & 31.8 & 49.2 \\
\hline Yrgalem, urban & 28.5 & 74.9 \\
\hline Jimma, urban & 39.7 & 81.3 \\
\hline Number of women $=1,750$ & & 69.2 \\
\hline
\end{tabular}


of those sample reported that their husband approved of prenatal care. Use of prenatal care varies substantially by whether the pregnancy was wanted and by husband's approval of prenatal care. Seventy-seven percent of women who wanted their pregnancy were found to have used prenatal care compared to 62 percent of the women who did not want their pregnancy. The difference was even larger for a husband's approval. Eighty percent of the women who reported that their husband approved of prenatal care actually used prenatal care services, compared to only forty percent of the women who reported their husband did not approve of prenatal care.

The study population was very diverse in terms of education, ethnicity and religion. Approximately onethird of the women in the sample had no schooling, whereas close to forty percent had some education beyond the primary school level. The men on average tended to have higher levels of education than the women in the sample - only 15 percent of husbands had no schooling while 60 percent had more than a primary school level education. Sidama, Oromo, and Amhara were the three most prevalent ethnic groups in the sample, Sidama being the most numerous of the three groups (39 percent). Close to one-half of the women are Orthodox Christians and another one-third are Protestants. Around one in six women are Muslims (18 percent), while 3 percent practice other religions. The distribution of men's ethnicity closely mirrors that of the women. Because marriage between men and women of different religions is relatively uncommon in the study area, the survey did not record husband's or partner's religion. The basic relationships between education and prenatal care, and ethnicity and prenatal care are the same for women and men. Higher levels of education (whether men's or women's) are associated with a greater likelihood of using prenatal care. Prenatal care is also most common among the Amhara and Oromo, and least common among the Sidama.

Other variables that show a strong relationship with prenatal care utilization are union type, prior use of prenatal care, and place of residence. Women in stable unions are 50 percent more likely than women in unstable unions (72 percent compared to 49 percent) to use prenatal care, and women who had used prenatal care during a prior pregnancy are 50 percent more likely to use prenatal care during the most recent pregnancy than women with no prior prenatal care experience (85 percent compared to 56 percent). As expected, use of prenatal care is more common in urban areas than in rural areas. Eighty-one percent of the women in Jimma Town and 75 percent of the women in Yirgalem town have used prenatal care compared to 49 percent of the women in rural areas outside Yirgalem town.

Figure 1 presents Kaplan-Meier estimates of the survival curves for time of first use of prenatal care by whether the pregnancy was wanted and whether the husband approves of prenatal care. The two lowest curves correspond to women who wanted their last pregnancy, and women with husbands who approved of prenatal care. Both curves are virtually identical with

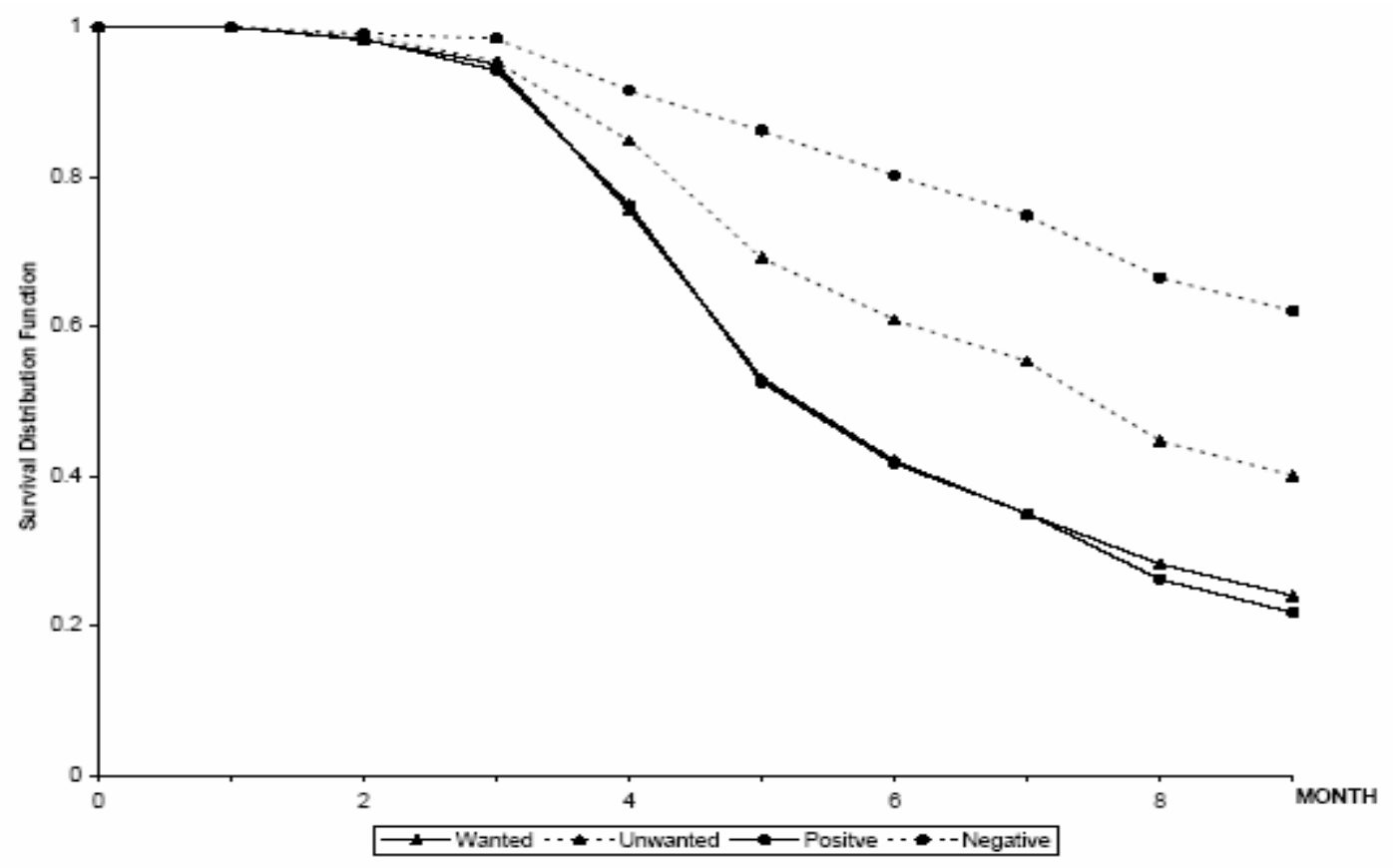

Figure 1: Kaplan-Meier Survival Curves for Time of First Prenatal Visit by Pregnancy Wantedness and Husband's Approval of Prenatal Care, Women of Reproductive Age with at Least One Live Birth, Yirgalem and Jimma Survey of Maternal Health, 1997

Ethiop.J.Health Dev. 2006;20(2) 


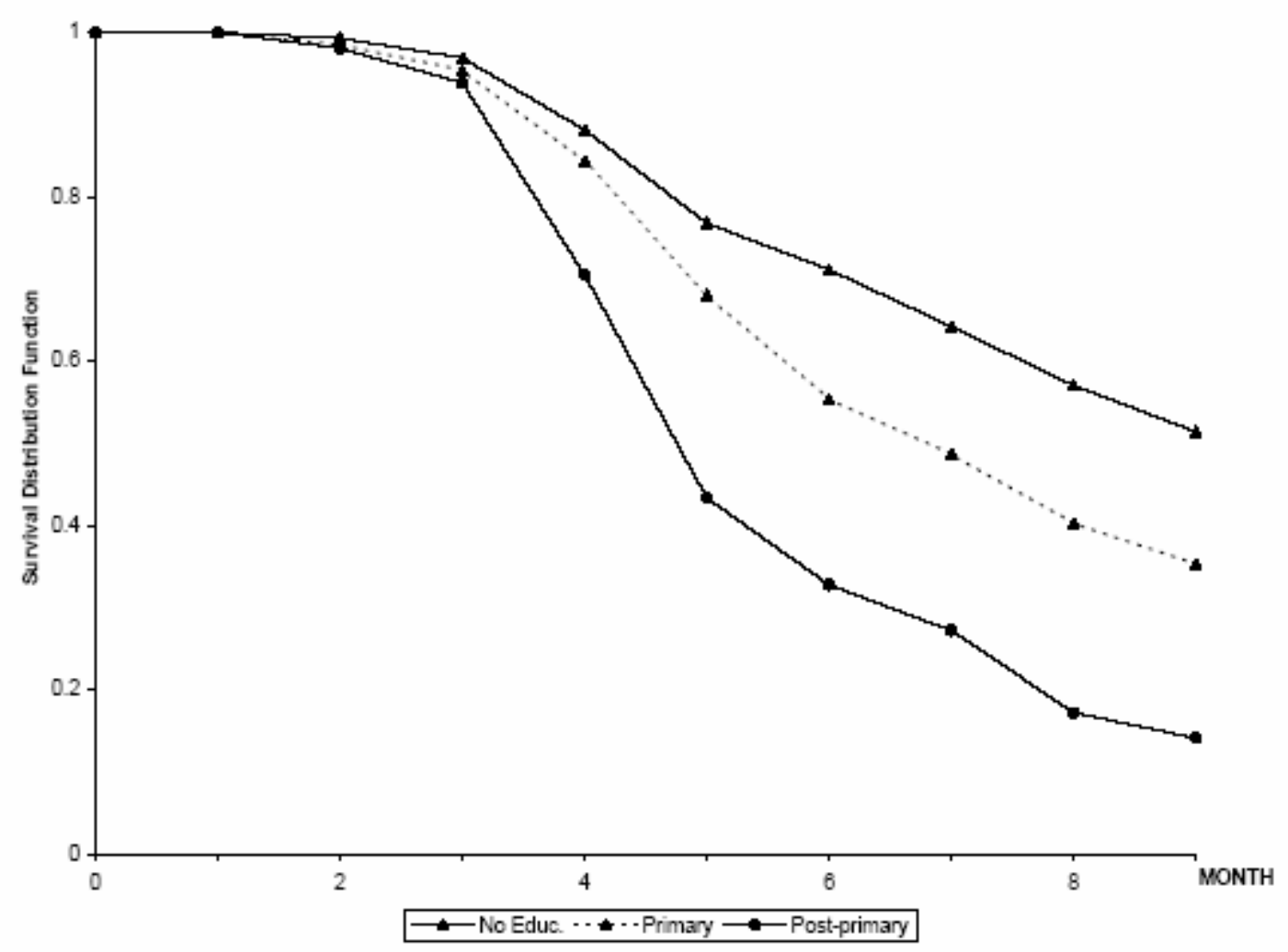

Figure 2: Kaplan-Meier Survival Curves for Time of First Prenatal Visit by Woman's Education, Women of Reproductive Age with at Least One Live Birth, Yirgalem and Jimma Survey of Maternal Health, 1997

median durations of approximately 5 months. The survival curve at the top corresponds to women whose husbands did not approve of prenatal care. The median for this group cannot be calculated because less than 50 percent of these women have used prenatal care. The intermediate curve corresponds to women who did not want their last pregnancy. Figure 1 reveals a very strong relationship between a husband's approval and a woman's use of prenatal care. Not only is the relationship highly significant (based on the log-rank test), it is also associated with a greater difference in the use of prenatal care than is the case with whether the pregnancy was wanted. For comparison purposes, Figure 2 presents Kaplan-Meier estimates of the survival curves for time of first use of prenatal care by a woman's education. Women's education is commonly considered in health services literature as a powerful intervention tool for raising health awareness and health-care utilization. The difference in the survival curves between having a husband who approves of prenatal care and having a husband who does not, is similar in magnitude to the difference between having no schooling and having postprimary schooling.

The descriptive statistics show a strong relationship between a husband's approval of prenatal care and a woman's health seeking behavior. The strength of this relationship appears to be greater than the relationship between a woman's own characteristics, such as pregnancy wantedness and education, and use of prenatal care. Multivariate regression models were next used to: (1) determine whether wanting a pregnancy and approval of prenatal care are co-determined; (2) estimate the effect of husband's approval of prenatal care on care utilization controlling for other factors; and (3) determine whether the influence of husband's approval varies (interacts) with a woman's age and education.

The determinants of pregnancy wantedness and approval of prenatal care

Table 2 presents parameter estimates from the bivariate probit model predicting a whether a woman wanted the pregnancy and her husband's approval of prenatal care. The bivariate probit model jointly estimates the effects of a woman's and her husband's characteristics on the two outcomes. The model includes a correlation term for the two regressions, but does not impose a causal order on the dependent variables. The independent variables in the model include education, ethnicity, religion, sexual preference for the most recent pregnancy, type of union, age of the woman, parity, prior infant death, prior use of prenatal care, and place of residence. The survey measured the education and ethnicity of both the respondent and her husband or partner, but it only measured religion and sex preference for the respondent. 
As mentioned earlier, because most unions are homogamous with respect to religion, a woman's religion was used in this study as a proxy measure of husband's religion.

Significant determinants of wanting a pregnancy include education, religion, type of union, age, parity, and the prior death of an infant. Women with post-primary education are significantly more likely than women with a primary level education or less, to have wanted their most recent pregnancy. Though there appear to be no ethnic differences in wanting a pregnancy after controlling for other factors, religion does seem to matter. Protestant women were found to be more likely to have wanted their most recent pregnancy than Orthodox women. Age and a history of prior infant death were also found to be positively related to wanting the most recent pregnancy. Women in unstable unions and women at higher parities were significantly less likely to have wanted their most recent pregnancy than women in stable unions and women at the outset of childbearing.

The determinants of a husband's approval of prenatal care are very similar to those for pregnancy wantedness. A husband's education was positively related to approval of prenatal care, as is the woman's age, whereas being in an unstable union and high parities were both related to significantly lower likelihoods of approving prenatal care. In the case of men, ethnicity matters, but religion does not appear to be important. Women in union with men from the Amhara ethnic group were more likely to report that their partner approves of prenatal care than women who are married to Sidama men. Prior experience with prenatal care and place of residence are also important. The husbands of women who used prenatal care in the past, and the husbands of women living in Yirgalem or Jimma Town, are more likely to approve of prenatal care.

Table 2: Parameter Estimates from Bivariate Probit Model Predicting Woman Wanted Most Recent Pregnancy and Husband Approves of Prenatal Care, Yirgalem and Jimma Survey of Maternal Health, 1997

\begin{tabular}{|c|c|c|c|c|}
\hline \multirow[b]{2}{*}{ Variables } & \multicolumn{2}{|c|}{$\begin{array}{l}\text { Wife wanted } \\
\text { pregnancy }\end{array}$} & \multicolumn{2}{|c|}{$\begin{array}{l}\text { Husband approves of } \\
\text { prenatal care }\end{array}$} \\
\hline & $\beta$ & & \multicolumn{2}{|c|}{$\beta$} \\
\hline \multicolumn{5}{|c|}{ Education (ref = No schooling) } \\
\hline Primary & 0.035 & & 0.406 & $* *$ \\
\hline Post-primary & 0.189 & * & 0.602 & ** \\
\hline \multicolumn{5}{|c|}{ Ethnicity (ref = Sidama) } \\
\hline Oromo & -0.156 & & 0.388 & * \\
\hline Amhara & -0.154 & & 0.589 & ** \\
\hline Others & -0.107 & & 0.404 & $* *$ \\
\hline \multicolumn{5}{|c|}{ Woman's Religion (ref = Orthodox) } \\
\hline Protestant & 0.107 & & -0.099 & \\
\hline Muslim & 0.093 & & -0.160 & \\
\hline Other & 0.142 & & -0.332 & \\
\hline \multicolumn{5}{|c|}{$\begin{array}{l}\text { Woman's sex preference for most recent birth } \\
\quad \text { (ref = No preference) }\end{array}$} \\
\hline Son & -0.130 & & 0.182 & * \\
\hline Daughter & -0.101 & & 0.169 & \\
\hline \multicolumn{5}{|c|}{ Union type (ref = Stable) } \\
\hline Unstable & -1.491 & ** & -1.783 & ** \\
\hline \multicolumn{5}{|c|}{ Woman's Age (ref $\leq 20$ ) } \\
\hline $20-24$ & 0.142 & & 0.573 & $* *$ \\
\hline $25+$ & 0.287 & * & 0.603 & ** \\
\hline \multicolumn{5}{|l|}{ Parity (ref = 1) } \\
\hline $2-3$ & -0.715 & ** & -0.440 & ** \\
\hline $4-5$ & -0.867 & ** & -0.715 & ** \\
\hline $6+$ & -1.419 & ** & -0.700 & $* *$ \\
\hline \multicolumn{5}{|c|}{ Prior infant death (ref $=$ None) } \\
\hline One or more & 0.400 & ** & 0.159 & \\
\hline Prior prenatal care $\iota$ & & & & \\
\hline Yes & 0.098 & & 0.429 & ** \\
\hline \multicolumn{5}{|c|}{ Place of residence (ref = Yirgalem, rural) } \\
\hline Yirgalem, urban & 0.039 & & 0.087 & \\
\hline Jimma, urban & -0.001 & ** & 0.001 & \\
\hline Rho & -0.023 & & & \\
\hline Number of couples & 1,750 & & & \\
\hline
\end{tabular}


Even though there are similarities in the underlying determinants of pregnancy wantedness and a husband's approval of prenatal care, the two attitudes are independently determined. The estimate of the correlation coefficient (rho) was not significantly different from zero. The significance of this finding for the analysis in this study is that pregnancy wantedness and the approval of prenatal care are not reflections of one another; rather they are independently determined. Taking into consideration a woman's thoughts or feelings about a pregnancy is not the equivalent of taking into consideration her husband's position on prenatal care.
The next section assesses the relative impact of whether a woman wanted the pregnancy and whether her husband approves of prenatial care on her use of prenatal care services.

The determinants of prenatal care utilization

The determinants of prenatal care utilization were examined using a complementary log-log regression model. Table 3 presents the results from the complementary log-log model predicting prenatal care. Both pregnancy wantedness and a husband's approval of prenatal care are highly significant predictors of prenatal

Table 3: Parameter Estimates from Complementary Log-Log Regression Model Predicting First Prenatal Care Visit for last Pregnancy that Resulted in a Live Birth. Yirgalem and Jimma Survey of Maternal Health, 1997

\begin{tabular}{|c|c|c|c|c|c|c|}
\hline & Model 1 & & Model 2 & & Model 3 & \\
\hline Variables $^{a}$ & $\beta$ & & $\beta$ & & $\beta$ & \\
\hline Woman wanted pregnancy & 0.388 & ** & 0.384 & ** & 0.389 & ** \\
\hline Husband approves of prenatal care & 0.799 & ** & 1.251 & ** & 0.737 & ** \\
\hline \multicolumn{7}{|l|}{ Woman's education (ref = no schooling) } \\
\hline Primary & 0.168 & & 0.164 & & 0.228 & \\
\hline Post-primary & 0.443 & ** & 0.445 & ** & 0.205 & \\
\hline \multicolumn{7}{|l|}{ Woman's ethnicity (ref = Sidama) } \\
\hline Oromo & 0.106 & & 0.110 & & 0.101 & \\
\hline Amhara & 0.287 & * & 0.280 & * & 0.282 & * \\
\hline Other & 0.102 & & 0.097 & & 0.096 & \\
\hline \multicolumn{7}{|l|}{ Woman's religion (ref $=$ Orthodox) } \\
\hline Protestant & 0.046 & & 0.049 & & 0.045 & \\
\hline Muslim & 0.066 & & 0.064 & & 0.068 & \\
\hline Others & 0.215 & & 0.224 & & 0.199 & \\
\hline \multicolumn{7}{|l|}{$\begin{array}{l}\text { Woman's sex preference for most recent birth } \\
\text { (ref = No preference) }\end{array}$} \\
\hline Son & 0.217 & ** & 0.224 & ** & 0.215 & ** \\
\hline Daughter & 0.162 & * & 0.154 & * & 0.159 & * \\
\hline \multicolumn{7}{|l|}{ Union type (ref = Stable) } \\
\hline Unstable & -0.406 & ** & -0.386 & ** & -0.378 & ** \\
\hline \multicolumn{7}{|l|}{ Woman's age (ref $=<20$ ) } \\
\hline $20-24$ & 0.173 & & 0.554 & * & 0.169 & \\
\hline $25+$ & 0.244 & * & 0.667 & ** & 0.233 & * \\
\hline \multicolumn{7}{|l|}{ Parity $($ ref $=1)$} \\
\hline $2-3$ & -0.599 & ** & -0.609 & ** & -0.603 & ** \\
\hline $4-5$ & -0.623 & ** & -0.633 & ** & -0.618 & ** \\
\hline $6+$ & -0.862 & ** & -0.876 & ** & -0.860 & ** \\
\hline \multicolumn{7}{|l|}{ Prior infant death experience $(r e f=\mathrm{No})$} \\
\hline One or more & 0.130 & & 0.128 & & 0.130 & \\
\hline \multicolumn{7}{|l|}{ Prior prenatal care utilization $(\mathrm{ref}=\mathrm{No}$ ) } \\
\hline Yes & 0.872 & ** & 0.883 & ** & 0.873 & ** \\
\hline \multicolumn{7}{|l|}{ Place of residence (ref= Yirgalem, rural) } \\
\hline Yirgalem, urban & 0.300 & ** & 0.307 & ** & 0.305 & ** \\
\hline Jimma urban & 0.679 & ** & 0.683 & ** & 0.680 & ** \\
\hline \multicolumn{7}{|l|}{ Duration in trimester (ref= $1^{\text {st }}$ Trimester) } \\
\hline $2^{\text {nd }}$ Trimester & 1.237 & ** & 1.238 & ** & 1.241 & ** \\
\hline $3^{\text {rd }}$ Trimester & 1.208 & ** & 1.214 & ** & 1.215 & ** \\
\hline \multicolumn{7}{|l|}{ Interactions } \\
\hline Woman age $20-24 \times$ Husband approves & & & -0.511 & * & & \\
\hline Woman age $25+\times$ Husband approves & & & -0.555 & * & & \\
\hline Woman primary $\times$ Husband approves & & & & & -0.070 & \\
\hline Woman post-primary $\times$ Husband approves & & & & & 0.276 & \\
\hline \multicolumn{7}{|l|}{ Number of trimesters $=3,942$} \\
\hline \multicolumn{7}{|l|}{ Number of women $=1,750$} \\
\hline Log-likelihood & -1957.0 & & -1954.1 & & -1955.4 & \\
\hline
\end{tabular}


care utilization. Women who wanted their pregnancy are $1.5\left(\mathrm{e}^{0.388}\right)$ time as likely to have used prenatal care as women who did not want their pregnancy, and women whose husband approves of prenatal care as women who did not want their pregnancy, and women whose husband approves of prenatal care are $2.2\left(\mathrm{e}^{0.799}\right)$ times as likely to have used prenatal care as women whose husband did not approve of prenatal care. Other factors associated with a significantly higher likelihood of prenatal care utilization include: having post-primary education, living in towns, prior use of prenatal care, Amhara ethnicity, preference for either a boy or a girl as compared to having no sex preference, and being age 25 or above. Factors associated with a significantly lower likelihood of using prenatal care include being in an unstable union compared to a stable union and having other children.

The final question this article addresses is whether the influence of a husband's approval on a women' use of prenatal care varies by a women's age and education. Two separate interaction models are estimated: Model 12 includes the interaction between a women's age and a husband's approval of prenatal care, and Model 3 includes the interaction between a woman's education and a husband's approval. In Model 2 both of the interaction terms were found to be negative and statistically significant, indicating that the influence of a husband's approval of prenatal care on care utilization declines with a woman's age. Among women under the age of 20, having a husband who approves of prenatal care increases the likelihood of using prenatal care by a factor of $3.5\left(\mathrm{e}^{1.251}\right)$. For older women, husband's approval is still an important determinant of prenatal care utilization, but the magnitude of the effect is smaller. Among women aged 20-24, having a husband who approves of prenatal care increases the likelihood of care utilization by a factor of $2.1\left(\mathrm{e}^{1.251-0.511}\right)$, and among women aged 25 and above it increases care utilization by a factor of $2.0\left(\mathrm{e}^{1.251-0.555}\right)$. This finding is consistent with the expectation of greater decision making autonomy among older women compared to younger women. In contrast to significant age interactions, the interactions between education and a husband's approval were not found to be statistically significant (Model 3).

\section{Discussion}

Studies of maternal health provide strong evidence of the beneficial effects of early prenatal care on fetal development and the process of giving birth. While cost and availability are major barriers to accessing prenatal care in many developing countries, lack of awareness of the importance of prenatal care and restrictions on women's health seeking behavior stemming from husband's disapproval remain as important barriers to prenatal care utilization even in areas where services are available. Many interventions designed to increase maternal health-care program awareness and acceptance focus on women's characteristics and attitudes. In this article couple data on women's and men's characteristics and attitudes were used to examine the relationship between pregnancy wantedness and husband's approval of prenatal are, and to estimate the relative importance of a husband's approval on prenatal care utilization. The first finding that the determination of a husband's approval of prenatal care is unrelated to whether a woman wanted the pregnancy has important implications for designing program interventions. Messages that target men can have a potentially positive effect on prenatal care utilization independent of whether the wife wanted the pregnancy.

The second major finding is that the influence of a husband's approval on the use of formal prenatal care services is not trivial and, in fact, is larger in magnitude than the effect of whether the pregnancy was wanted, and the effect is larger than the effect of a woman's education. Estimates from a complementary log-log hazard regression model showed that women married to men who approved of prenatal care were over twice as likely to use prenatal care during their last pregnancy as women whose husbands did not approve of prenatal care. By comparison, women who wanted their last pregnancy were found to be 50 percent more likely to use prenatal care than women who did not want their pregnancy, and women with post-primary schooling were 55 percent more likely to use prenatal care than women with no schooling. Using interaction terms, it was also found that the impact of a husband's approval on a woman's health seeking behavior varied by a woman's age and was greatest among women under the age of 20 .

The results of the analyses in this study highlight the importance of taking into account a husband's attitudes when designing interventions intended to raise the use of formal prenatal-care services. Informational programs that target young couples and in particular the husbands of adolescent mothers can have potentially large effects on increasing the likelihood that pregnant women seek out formal prenatal care early in their pregnancies.

\section{Acknowledgements}

Work on this study was supported by grants from the David and Lucile Packard Foundation, the Compton Foundation and the Mellon Foundation.

\section{References}

1. Royston E, Armstrong A. Preventing maternal death. WHO, Geneva, Switzerland. 1989.

2. Donaldson JP, Billy JO. The impact of prenatal care on birth-weight: Evidence from an international data set. Medical Care 1988;22(2):177-188.

3. Central Statistical Authority and ORC Macro. Ethiopia Demographic and Health Survey 2000. Addis Ababa, Ethiopia and Calverton, Maryland USA, 2001.

4. Rosoff JT. An interlocking agenda. Family Planning Ethiop.J.Health Dev. $\quad 2006 ; 20(2)$ 
Perspectives 1985;17:100.

5. Fantahun M, Olwit G, Shamebo D. Determinants of antenatal care attendance and preference of site of delivery by pregnant women in Addis Ababa. Ethiop J Health Dev.1992;6(4):17-21.

6. Mesfin M, J.Farrow. Determinants of antenatal care utilization in Arsi Zone, Central Ethiopia. Ethiop J Health Dev. 1996;10(3):171-178.

7. Wakbulcho M, Moller B. Attitude toward current pregnancy among women attending an antenatal clinic in Ethiopia. Inter $\mathrm{J}$ Gynecol Obstet. 1994;46(1):61-62.

8. Dharmalingam A, Hussain T.M, Smith J.F. Women's education, autonomy, and utilization of reproductive health services in Bangladesh. In: A.I. Mundigo (Eds.) Reproductive health: Program and policy change post Cairo. Liege, Belgium, IUSSP, 1999.
9. Thomson E. Two into one: Structural models of couple behavior. In: Draper CW and Marcos AC (eds.), Family variables: Conceptualization, measurement and use, Newbury Park, CA, 1990;129-142.

10. Central Statistical Authority. The 1994 Population and Housing Census of Ethiopia. Addis Ababa, Ethiopia, 1999.

11. Greene WH. Estimation of correlation coefficient in a Bivariate Probit Model using the Method of Moments. Economics Letters 1984;16:285-291.

12. Greene WH. LIMDEP Version 7.0 User's Manual, Bellport, NY, USA 1995. 